\title{
Evaluating and predicting risk to a large reptile (Varanus varius) from feral cat baiting protocols.
}

Tim S. Jessop ${ }^{\text {A, }}$, Michael R. Kearney ${ }^{\text {A }}$, Joslin L. Moore ${ }^{\mathrm{B}}$, Tim Lockwood ${ }^{\mathrm{A}}$ and Michael Johnston $^{\mathrm{C}}$

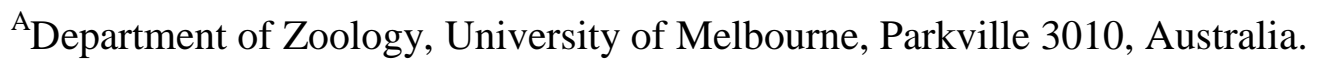

B Australian Research Centre for Urban Ecology, Royal Botanic Gardens, Melbourne, c/o School of Botany, University of Melbourne, Victoria 3010 Australia.

${ }^{\mathrm{C}}$ Arthur Rylah Institute, Department of Sustainability and Environment, Heidelberg 3084, Australia. 


\section{Abstract}

Control of introduced predators to mitigate biodiversity impacts is a pressing conservation challenge. Across Australia feral cats (Felis catus) are a major threat to terrestrial biodiversity. Currently feral cat control is hindered by the limited utility of existing predator baiting methods. Further proposed control methods include use of the novel poison para-aminopropiophenone (PAPP) which may present a hazard to some native animal populations. Here we used experimental and predictive approaches to evaluate feral cat bait take by a large native Australian predatory reptile the Lace monitor (Varanus varius). These lizards would be expected to readily detect, ingest and consume a lethal dose (depending on toxin) from surface-laid baits intended for feral cat control if a precautionary approach was not adopted when baiting. We modelled $V$. varius bait take using experimental and predictive biophysical modelling approaches to evaluate temporal effects of climate variables on $V$. varius activity and hence potential for bait removal. Finally we conducted a pre-PAPP baiting site occupancy assessment of $V$. varius within Wilson Promontory National Park (WPNP) to provide a basis for monitoring any longer term population effects of cat baiting. V. varius removed $7 \%$ of deployed baits from $73 \%$ of bait stations across another study area in Far Eastern Victoria. Daily bait removal was positively correlated with maximum temperature and solar radiation. Biophysical modelling for Far Eastern Victoria predicted that maximum temperatures $<19.5^{\circ} \mathrm{C}$ prevented $V$. varius activity and hence opportunity for bait removal. $V$. varius in WPNP was undetectable suggesting aerial baiting posed limited hazard to this species at this location. Depending how climate influences annual activity patterns and the specific poison, surface-laid baits could pose a significant mortality risk to $V$. varius. 
However, use of biophysical models to predict periods of $V$. varius inactivity may provide a novel means to reduce non-target bait take by this predator.

Keywords: Introduced predators, poison baits, non-target risk, mechanistic niche models, Varanid Lizards, Varanus varius, Felis catus, para-aminopropiophenone 


\section{Introduction}

Introduced predators represent a major global threat to biodiversity (Owens and Bennett 2000; Croll et al. 2005; Saunders et al. 2010). Across Australia the European red fox (Vulpes vulpes) and feral cat (Felis catus) have been implicated in the decline of many native species (Dickman 1996; Risbey et al. 2000; Saunders et al. 2010). Consequently considerable resources are invested to mitigate introduced predator impacts to deliver Australia's conservation outcomes (Reddiex et al. 2006). For example, ongoing use of sodium monofluroacetate (1080) poison baits has been commonly used to suppress fox abundance at various scales across Australia leading to broad scale biodiversity gains (e.g. Kinnear et al. 2002; Saunders et al. 2010 ). However, in contrast such baiting methods are largely ineffective for feral cats due to low bait acceptability and because baiting protocols (eg. intensity and timing of bait deployment) can be less than optimal for cats (Short et al. 1997a; 1997b; Algar et al. 2007; Moseby et al. 2009; Moseby et al. 2011 ). Further, canid baiting programs may actually benefit cats, via mesopredator release, resulting in ongoing biodiversity impacts (Ritchie and Johnson, 2009).

Not surprisingly, reducing feral cat numbers via lethal control methods is considered key to reducing their biodiversity impact (DEWHA 2008). The Curiosity ${ }^{\circledR}$ bait, a sausage-style bait containing an encapsulated pellet that can contain lethal poisons including 1080 or para-aminopropiophenone (PAPP) is currently being evaluated for feral cat control in Australia (Johnston et al. 2010; Johnston et al. 2011). The Curiosity ${ }^{\circledR}$ cat bait incorporates several qualities that improve its specificity to cat consumption (Marks 2006; Hetherington et al. 2007; Forster 2009; Johnston et al. 2011). Nevertheless, recent studies indicate the Curiosity ${ }^{\circledR}$ bait is attractive to 
multiple non-target native species including two varanid lizards, (Varanus rosenbergi and V. gouldii) (Algar et al. 2007; de Tores et al. 2011).

These results highlight the need for target-specific bait take in complex faunal communities where conservation objectives are pertinent. A key component to reducing non-target bait consumption is for managers to identify "filter" opportunities representing strategies to reduce non-target bait take (Bengsen et al., 2008). For example, temporal and spatial adjustments of bait delivery can influence non-target bait take via reducing detection, interaction and access to the bait or its toxin (Bengsen et al. 2008; Bengsen et al. 2011; Moesby et al. 2009; Moesby et al. 2011).

Predictive methods offer a major advancement to limiting non-target bait take as they could identify filter opportunities. For example, if managers could reliably predict daily or seasonal activity patterns of non-target species it could provide a means to deploy baits to reduce non-target bait take. With the advent of mechanistic niche models (Kearney and Porter 2004; 2009) which predict the fundamental niche of organisms via coupling biophysical models of heat and mass transfer of animals and their microclimates (Porter 1989; Porter et al. 1973) this is potentially possible. These models can predict activity of animals over different time scales (hourly, daily and seasonally) and have proved highly effective for predicting the effects of current and future climate on activity patterns (and ensuing implications) in ectothermic vertebrates such as reptiles and amphibians (Kearney et al. 2008; Kearney et al., 2009). As mechanistic niche models predict activity patterns of animals they could also have important applications that, in part, help estimate daily and seasonal levels 
of bait consumption and ultimately mortality risk to non-target, and potentially threatened, native species.

As currently developed, biophysical models have immediate application to predicting activity profiles of Australia's ectothermic predators, including the large varanid lizards (1-2m long) which are a common and often multi species component of terrestrial predator guilds likely to compete with cats for any surface-laid bait deployment. In addition to considerable dietary overlap with cats (Jessop et al. 2010), these lizards are highly active and can be expected to readily detect and ingest cat baits (Sutherland et al. 2011). Therefore, large-scale cat baiting programs could significant varanid lizard mortality (depending on toxin) if baits were available during periods of reptile activity (de Tores et al. 2011; Sutherland et al. 2011). For example, if Curiosity ${ }^{\circledR}$ baits are used in conjunction with PAPP, despite mammalian carnivores being more susceptible to PAPP than most non-target species tested, there is evidence that PAPP tolerance in reptiles is also low (S. Humphrys pers. comm. in Murphy et al. 2011). Thus varanid lizards are clearly at risk of non-target mortality due to predator baiting programs using PAPP.

Whilst risk of mortality of native species to toxic baiting is often estimated using captive feeding trials, mortality estimates under field conditions, beyond anecdotal, are rarely undertaken for native species making it difficult to fully evaluate the costs of baiting programs to native animal populations (Choquenot and Ruscoe, 1999; Davidson and Armstrong 2002; Veltman and Westbrooke 2011). Hence in addition to identifying filter opportunities that reduce exposure of non-target species to toxic baits it is desirable to also conduct pre- and post baiting population monitoring of 
non-target species to directly quantify risk from predator baiting programs (Davidson and Armstrong 2002). The justification for such monitoring is to first ensure there are no negative population consequences for native non-target species. Second non-target species monitoring could also prevent undesirable consequences that may arise due to alteration in species composition and interactions brought on by baiting induced changes to target and non-target species. Such changes could have cascading ecological effects throughout the baited area and lead to undesirable biodiversity outcomes (Chapin et al. 2000; Courchamp et al. 2003).

Here we aimed to develop a comprehensive protocol using experimental, predictive modelling approaches and population monitoring to evaluate risk of non-target consumption of feral cat baits by a large Australian reptile predator, the Lace monitor (Varanus varius). Specifically our aims were to:

1. Estimate via models the influence of environmental parameters, on consumption rates of non-toxic Curiosity ${ }^{\circledR}$ baits by $V$. varius across coastal forest in Far East Gippsland, Victoria.

2. Use biophysical models to predict the effects of environmental parameters on lizard activity and hence annual patterns when this lizard could be expected to ingest baits. Additionally we assessed the relationship between daily bait take (Aim 1) and the amount of daily activity predicted by the biophysical models. This determined how correlated predicted daily activity and daily lizard bait take was during peak activity periods during summer in Far East Victoria. We expected biophysical models to predict strong seasonal variation in Lace Monitor activity, especially long bouts of inactivity given the temperate clime of our study 
site. Additionally, a greater benefit of these models would be to predict bouts of daily inactivity due to large daily thermal variation in this region during summer, enabling increased periods of baiting to better control feral cats whilst maintaining low bait take in varanids.

3. To undertake a population monitoring assessment of $V$. varius in Wilson Promontory National Park (WPNP) prior to an experimental aerial PAPP baiting trial. An estimate of site occupancy for this species across the intended baited area would help provide a pre-baiting population index to compare subsequent changes in occupancy that could identify any potential effects of PAPP baiting on this species.

\section{Material and Methods}

\section{Field Sites}

We utilised a field site in Far East Gippsland (FEG) (37 $\left.42^{\circ} \mathrm{S}, 148^{\circ} 40^{\prime} \mathrm{E}\right)$ Victoria, Australia (Fig. A.1) that comprised 18000 ha of coastal Eucalypt forest and Banksia woodland within Cape Conran State Park and adjacent Murrungowar State Forest. Here we conducted $V$. varius bait removal evaluation and site occupancy monitoring. We chose this site because prior research (Jessop et al. 2012) show lace monitors were locally abundant. 
At the second site in Wilsons Promontory National Park (WPNP) (38 59'S, 146

${ }^{\circ} 22$ 'E) we conducted site occupancy monitoring for $V$. varius within $\sim 35000$ ha of

Eucalypt forest and Banksia woodland. Fieldwork took place between November 2010 and February 2011 coinciding with the highest period of activity of $V$. varius in Southern Australia during summer.

\section{Bait Take Evaluation}

At the FEG site we established 60 bait monitoring stations spaced at $2 \mathrm{~km}$ intervals where we deployed 1686 Curiosity ${ }^{\circledR}$ baits over 29 days during November/December 2010 and January/February 2011(Fig. A.1). The Curiosity ${ }^{\circledR}$ bait has been developed by collaborative research undertaken by the DSEWPaC, DEC-WA, DSE - Victoria and Scientec Research Pty Ltd. The bait matrix is patented under Patent No. AU 781829 and the toxicant encapsulation technology by Australian Provisional Patent Application 2008903572. Curiosity ${ }^{\circledR}$ is a registered trademark owned by the Australian Government.

All bait stations were established in forest adjacent to management tracks. At each bait station we constructed a $1 \mathrm{~m}^{2}$ sand pad from beach sand to enable the identification of species visiting the site from spoor. The Curiosity ${ }^{\circledR}$ bait was placed on the surface in the middle of each sand pad. Baits were dispensed onto sand pads in the mid afternoon to facilitate increased specificity of bait take by introduced predators that are typically more crepuscular or nocturnal relative to diurnally active varanids. 
For any bait station where baits were removed, we replaced (again in the mid afternoon) the bait to ensure that all 60 sites were functional on a daily basis. New baits were placed for all bait stations every fourth day to ensure uniform bait condition (i.e. shape and smell) throughout the study.

To validate species-specific track identifications we rotated 30 wildlife cameras (Scout Guard SG550V) to record photos of visiting animals. Cameras were rotated among all bait stations throughout the study period. Bait stations were checked daily and the frequency of bait consumption, species of animal responsible for consumption (based on interpretation of field sign and photos) recorded. All bait stations were tended daily (i.e. fallen leaves removed and sand pad surfaces smoothed flat) to further standardise the uniformity of detection.

Biophysical models to predict $V$. varius activity.

The biophysical models, collectively called Niche Mapper, included a microclimate model and an animal model (Porter and Mitchell 2006). The microclimate model uses daily macroclimatic data as well as topographic and location data (sourced from the Mallacoota Weather Station in Far East Gippsland) to reconstruct hourly microclimatic conditions (Porter and Mitchell 2006; Kearney and Porter 2009). These included hourly changes in solar and infrared radiation, humidity, cloud cover, surface temperatures, and subsoil temperatures as well as air temperature and wind speed profiles above ground. The animal model solves coupled energy and mass balance equations to find suitable core temperatures within the available microclimates as a function of empirically determined behaviour, morphology, and physiology of $V$. 
varius (Porter et al. 1973). We used the settings reported in Kearney and Porter (2004) except that we used values of 17 and $40{ }^{\circ} \mathrm{C}$ for voluntary thermal minimum and maximum body temperatures for foraging and $35^{\circ} \mathrm{C}$ for preferred body temperature (Bartholomew and Tucker, 1964), assuming a body solar reflectivity of $7 \%$ (derived from the similar coloured congeneric, V. rosenbergi, Christian et al., 1996) and an average body mass of $4 \mathrm{~kg}$ (Jessop unpublished data).

Pre-baiting site occupancy estimates of $V$. varius

Prior to a planned aerial PAPP baiting trial in WPNP we conducted a site occupancy assessment of $V$. varius across 32 detection sites that were monitored for 22 days using up to three concurrent monitoring methods (traps, sand pads and cameras). Traps comprised aluminium box traps $(2 \mathrm{~m} \times 0.3 \times 0.3 \mathrm{~m})$ purpose built for $V$. varius (Fig. A.2). Traps were baited with chicken drumsticks infused with tuna oil. Sand pads (similar dimensions as above) were located within $100 \mathrm{~m}$ of traps and baited with chicken meat covered with tuna oil as an attractant. Monitoring commenced in mid February and finished in mid March of 2011. Composite detection sites were established along $17 \mathrm{~km}$ of management tracks. However as management tracks were limited to often sparse open vegetation that were perceived to be relatively poor quality habitat for $V$. varius, an additional 16 camera only sites were established up along the Vereker range (up to $400 \mathrm{~m}$ ASL) over approximately $12 \mathrm{~km}$ of undisturbed forest. To improve detection of $V$. varius at these camera only sites tuna oil was deposited at $\sim 2 \mathrm{~m}$ in front of the camera to provide a scent lure. We treated sites as "composite sites" or "camera only" sites to standardise detection differences between sites utilising three detections methods versus one detection method. 
In addition, we evaluated the site occupancy of $V$. varius in FEG, based on their detection at the 60 bait stations using the protocols outlined above for determining $V$. varius bait take at each site. We considered site occupancy at FEG as a reference site, as our prior research here had indicated that $V$. varius were common and successfully detected by our field methods. Thus FEG acted as a control site to WPNP where we had no prior knowledge of the relative population abundance of this species.

Statistical Analyses

Bait Removal Study.

To model the relationship between total daily bait removal and environmental covariates, a Bayesian information-theoretic approach was adopted (Spiegelhalter et al., 2002). Multiple hypotheses were considered relating the effects of environmental variables (daily maximum temperature, daily solar radiation load and rainfall data sourced from Australian Bureau of Meteorology weather stations (Cabbage Tree Creek and Orbost \#2) to lizard activity and their ensuing ability to remove baits. These variables were identified apriori as ecologically plausible and measurable parameters characterising alternate hypotheses pertaining to $V$. varius activity. We constructed 6 models, including a null model (intercept only model), and estimated their relationship on the probability of $V$. varius bait removal using generalized linear mixed effect models incorporating a binomial error with a logit link; bait station was incorporated as a random term in models. 
The models were fitted to the data using Bayesian Markov Chain Monte Carlo (MCMC) methods within the package MCMCglmm (Hadfield 2010) using Program R (Version 2.13.1, R Development Core Team 2007). To represent a lack of prior information and to ensure that the parameter estimates were driven by the data we used uniform prior distributions for our data. Parameter estimates are based on 1000 iterations sub sampled from 65000 iterations after a 15000 sample burn-in and a thinning interval of 100 , which was more than sufficient for the MCMC chain to reach stationarity.

Deviance Information Criterion (DIC) was used to identify the relative support for each model (Spiegelhalter et al. 2002). The best-performing model has the smallest DIC and models were ranked from best to worst according to the differences between each model's DIC ( $\Delta \mathrm{i})$ values and model weight $(\omega)$.

Annual relationship between predicted activity and temperature.

To evaluate the annual relationship between the predicted $V$. varius daily activity (i.e. hrs of activity per day) estimates derived from Niche Mapper and maximum daily temperature three models were used. Our rationale for using multiple models was that the relationship between daily activity and maximum daily temperature could be eiter linear or non-linear.

The linear model was first considered,

$$
\text { Daily activity }=a+b \text { Temperature, }
$$


where $a$ is the intercept and $b$ is the slope of the relationship between $V$. varius daily activity and maximum daily temperature. Because the relationship between daily maximum temperature and daily activity durations could be nonlinear (eg. as temperature got too hot, lizards would reduce activity to seek shade), next we considered the power model,

$$
\text { Daily activity }=a(\text { Temperature })^{b} .
$$

Third the logistic model was considered,

$$
\text { Daily activity }=a /\left(1+b^{*} \exp ^{-c \text { Temperature }}\right) .
$$

Models were fitted using WinBUGS 1.4 (Lunn et al. 2000) called from the R package R2WINBUGS (Sturtz et al. 2005). Parameter estimates are based on 2400 samples sub sampled from 100000 samples taken from three chains after a 20000 burn-in and a thinning interval of 100, which was more than sufficient for WinBUGS to reach stationarity. Again models were ranked using Deviance Information Criteria (DIC) and we also included a null (intercept only) model to further benchmark performance of the three models. As an additional diagnostic measure of model fit $\mathrm{R}^{2}$ was estimated of the most parsimonious model where,

$$
\mathrm{R} 2=\sum \mathrm{i}(\operatorname{predicted}(\mathrm{yi})-\operatorname{mean}(\mathrm{y})) 2 / \sum \mathrm{i}(\mathrm{yi}-\operatorname{mean}(\mathrm{y}))^{2} .
$$

Relationship between bait take and predicted activity.

The relationship between probability of total daily bait take and predicted daily activity was estimated using an identical analytical and competing model approach as detailed directly above. 
Site Occupancy Estimates Model description.

Occurrence and detectability were modelled as two separate processes using the same approach as that used for hierarchical occupancy models (MacKenzie et al 2006). We modelled the occurrence of the species at site $i$ as a draw from the Bernoulli distribution with parameter $\psi$, which is the probability that the species occupies site $\mathrm{i}$ :

$$
\mathrm{Z}_{\mathrm{i}} \sim \operatorname{dbern}(\psi) .
$$

An occurrence is represented by $\mathrm{Z}_{\mathrm{i}},=1$, and an absence is represented by $\mathrm{Z}_{i},=0$. We assumed that a site was either occupied or not over all sampling occasions and that the probability that a site was occupied was the same for all sites.

We modelled the probability of detecting the species given it was present for a survey on day $j$ as a draw from the Bernoulli distribution with parameter $d_{j}$, which is the probability of detecting the species on day $\mathrm{j}$ given it was present. We allowed for heterogeneous detection between days using a random effect model with

$$
\operatorname{logit}\left(\mathrm{d}_{j}\right)=\operatorname{logit}\left(\mathrm{d}_{0}\right)+\xi_{j}
$$

and $\xi_{j}$ is drawn from a normal distribution with mean 0 and standard deviation $\sigma$. Hence, for each site and day we calculated:

$$
\mathrm{X}_{i, j} \sim \operatorname{dbern}\left(\mathrm{d}_{\mathrm{j}}\right)
$$

where a detection is represented by $\mathrm{X}_{i, j}=1$, and a failure to detect is represented by $\mathrm{X}_{i, j}=0$.

We then modelled our observations as the product of occupancy and detection:

$$
\mathrm{Ob}_{i, j}=\mathrm{Z}_{i} * \mathrm{X}_{i, j}
$$

An observation is represented by $\mathrm{Ob}_{i, j}=1$, and a failure to observe the species is represented by $\mathrm{Ob}_{i, j}=0$. Again we fit the model using WinBUGS 1.4. To represent a lack of prior information, and to ensure that the parameter estimates were driven by 
the data we used $[0,1]$ uniform prior distributions for the probability of occupancy $(\psi)$ and the detection probability intercept $\left(\mathrm{d}_{0}\right)$ and a $[0,10]$ uniform prior distribution for the standard deviation of the detection random effect $(\sigma)$ (McCarthy 2007). Parameter estimates are based on 16666 samples sub sampled from 100000 samples taken from each of three chains after a 20000 burn-in, which was more than sufficient for WinBUGS to reach stationarity.

\section{Results}

Environmental determinants of bait removal.

$V$ varius removed $116(6.9 \%)$ of the 1686 baits deployed across the 60 bait stations (as inferred from photographs and their highly distinctive field sign) (Fig. A.2). This ranked $V$. varius as the second highest bait consumer after native rats (Rattus fuscipes, R. lutreolus; 45.0\%) and above predatory birds (Australian Raven (Corvus coronoides) and Kookaburras (Dacelo novaeguineae); 5.7\%) and introduced predators (fox and feral cat; $3.9 \%$ ).

$V$. varius removed baits from $73 \%$ of the 60 bait stations and total daily bait removal ranged from 0 to $21.7 \pm 5.3 \%$ of available baits. $V$. varius bait removal was highly influenced by environmental variables with the most parsimonious model incorporating an interactive effect between daily maximum temperature and total daily solar radiation (Table1). This model received substantial support compared to the next best model incorporating the additive effects of daily maximum temperature and total daily solar radiation $(\triangle \mathrm{DIC}=5.09)($ Fig. 1 ; Table 1$)$ and the null model $(\Delta \mathrm{DIC}=47.72)$. Increased maximum daily temperature and solar radiation were 
positively correlated with bait removal. Whilst there was increase in bait removal with temperature, it was still evident that $V$. varius were able to remove baits during the coldest $\left(16.9^{\circ} \mathrm{C}\right)$ clear days encountered in our study during summer.

Biophysical modelling predictions of $V$. varius activity.

The annual relationship between daily $V$. varius activity and maximum daily temperature was best described by a logistic model $\left(R^{2}=0.43\right)$ that received substantial support relative to the alternate power, linear and null models (Table 2; Fig. 2a). Niche Mapper estimated that maximum daily air temperatures $\geq 19.5^{\circ} \mathrm{C}$ were necessary to permit $V$. varius activity in East Gippsland. Activity increased rapidly between 20 and $25{ }^{\circ} \mathrm{C}$ before rapidly asymptoting once daily maximum air temperatures exceeded $27^{\circ} \mathrm{C}$.

Thus the daily activity duration for $V$. varius was highly seasonal in Eastern Victoria (Fig. 2b). Prolonged bouts of daily cool temperature encountered during winter prevents $V$. varius activity. Further, for Eastern Victoria, where weather patterns remain relatively unstable until mid summer (January/February); frequent oscillation between periods of warm clear weather to cool, cloudy and often wet weather could limit daily activity during spring.

Relationship between daily bait take and predicted daily activity in $V$. varius.

Model ranking indicated that the linear function $\left(\mathrm{R}^{2}=32 \%\right)$ received most support followed by power, logistic and null models. Essentially this model described a subtle 
increase in daily bait take by $V$. varius increasing durations of predicted daily activity (Table 3, Fig. 3). There were some instances where the empirical data was not well matched by predicted activity estimates especially where Niche Mapper estimated the absence of daily activity in V.varius despite low bait take being measured.

Pre-baiting site occupancy estimate for $V$. varius.

In WPNP despite sampling over a large spatial area incorporating multiple habitat types during optimal warm weather conditions we were unable to detect the presence of $V$. varius within our monitoring area. Consequently in the absence of detections, $V$. varius site occupancy was assumed to be near zero or possibly absent in this area. This result was in stark contrast to the FEG site where our estimate of site occupancy $(\psi=0.78 \pm 0.06 ; 95 \% \mathrm{CI}=0.65-0.90)$ inferred that $V$. varius were very common across this study area (Table A.1).

\section{Discussion}

Across Australia introduced predator control represents a significant and ongoing conservation investment to limit biodiversity impacts (Reddiex et al. 2006; Saunders et al. 2010). Given that baiting protocols are rarely species specific it also entails varied risk to non-target native species and hence associated biodiversity costs (deTores et al. 2011; Bengsen et al. 2011). These non-target costs could vary considerably depending in part on the complexity of the faunal community, and in particular the number of species with functionally equivalent behavioural, physical or ecological traits that overlap with the target species interplaying with temporal, spatial 
and delivery aspects of the baiting protocols and toxicity of the poison (Bengsen et al. 2008) .

However to date, non-target impacts (eg. changes to density or survival) are rarely evaluated and hence any costs to native biodiversity are largely unknown (Glen et al. 2007; Choeqenot and Ruscoe, 1999; Veltman and Westbrooke 2011). However there is an ethical imperative to evaluate non-target impacts where they are sufficient to negate biodiversity benefits by impacting species with high conservation or ecological importance (Davidson and Armstrong 2002; Glen et al. 2007). Our findings clearly support that $V$. varius can remove and ingest surface-laid Curiosity ${ }^{\circledR}$ baits which will necessitate that land managers are adequately informed prior to using bait products. Depending on daily weather conditions up to $22 \%$ of baits per day were removed by varanids in summer in our study. In the event that baits containing PAPP were deployed under similar conditions to our study it would suggest that $V$. varius could face substantial mortality, depending on interactions with lizard density, bait density, climatic conditions and densities of other bait competitors occupying the landscape over which cat baits are deployed.

Empirical and predictive modelling suggested that $V$. varius bait removal and daily activity (and hence the time available to forage and seek baits) was highly sensitive to variation in both temperature and solar radiation. This effect was expected given the importance of these environmental parameters for regulating activity in ectotherms (Porter et al. 1973; Huey 1982). Biophysical models within Niche Mapper predicted that $V$. varius in Eastern Victoria (i.e. field sites within this study) was largely inactive from April through September (i.e. winter and early spring) and hence by default would limit any bait removal in Eastern Victoria at this time. Further there was a 
positive linear correlation between daily bait take and predicted activity during summer. However as this accounted for $<50 \%$ of the variance it is unlikely that biophysical models could be a useful tool to infer bait take during peak activity periods in summer. In part, this is not surprising, as biophysical models predict activity which, whilst correlated with daily bait take, cannot account for biotic interactions including competition for baits (eg. from native rats), that are also influencing rates of daily bait take by $V$. varius.

Our pre-monitoring population assessment could not detect $V$. varius within WPNP preventing a population estimate of site occupancy across the area identified for a subsequent aerial PAPP baiting trial. The absence of $V$. varius site occupancy in WPNP was in stark contrast to the estimate obtained for the FEG site (i.e. 80\% occupancy) conducted immediately prior to monitoring WPNP. The difference in occupancy estimates using analogous methodologies under ideal monitoring conditions gives us good reason to believe that the risk of PAPP poisoning to this species is low at this location. This is because baiting would be conducted during cooler months when the species is inactive and moreover as $V$. varius maybe simply absent from intended baiting area. No doubt had we detected this species it would have necessitated post-baiting monitoring to evaluate the putative effect of PAPP baiting on the $V$. varius. Given that most predator baiting programs do not consider the biodiversity costs of non-target bait it inevitably makes it difficult to evaluate the holistic cost/benefits for biodiversity arising from predator baiting programs (Chapin et al. 2000; Davidson and Armstrong 2002).

Here we have conducted empirical, predictive and non-target population monitoring activities to help ascertain, and lower, the risk of PAPP baiting to a non-target species. 
Moreover our results suggest that varanid lizards, common native predators, are likely to be impacted by PAPP cat baiting programs, if baiting takes place when these lizards are active. Managers will need to attempt to reduce non-target bait take by exploiting behavioural and biological differences between cats and varanid lizards (Bengsen et al. 2008; 2011). Biophysical models could help reduce potential nontarget bait removal by these common native predators by predicting the seasonal activity pattern for varanid lizards. To further reduce risk to Varanid lizards (and potentially other native species) use of alternative toxins (eg. varanids have a high tolerance to 1080; McIlroy et al. 1985) is also suggested where it might not be possible to enable temporal separation between cat baiting programs and varanid activity including much of Northern Australia. Finally, we advocate that further field trials be conducted to determine 1) how rapidly encapsulated PAPP degrades in the environment, and 2) whether varanid lizards would still ingest capsules after the surrounding bait material has degraded. Without answers to these questions, we can't completely rule out non-target mortality. 


\section{Acknowledgements}

An Early Career Research Award from the University of Melbourne to TSJ. MRK was supported by an Australian Research Council grant DP110102813 facilitating analytical components of this research. The research was carried out under research permits 10005634 from the Department of Sustainability and Environment, Victoria, and Animal Experimental Ethics Committee approval DSE AEC10.15.A (Department of Sustainability and Environment, Victoria) and 0911328.2 (University of Melbourne). Julie Quinn and Dave Algar provided useful comments on earlier drafts of the manuscript. 


\section{REFERENCES}

Algar D, Angus GJ, Williams MR, Mellican AE (2007) Influence of bait type, weather and prey abundance on bait uptake by feral cats (Felis catus) on Peron Peninsula, Western Australia. Conservation Science Western Australia 6: 109-149

Bartholomew GA, Tucker VA (1964) Size, body temperature, thermal conductance, oxygen consumption and heart rate in Australian varanid lizards. Physiol Zool 36: $199-218$.

Bengsen A, Leung LK-P, Lapidge SJ, Gordon IJ (2008) The development of targetspecific vertebrate pest management tools for complex faunal communities. Ecol Manage Restor 9: 209-216

Bengsen A, Leung L, Lapidge S, Gordon I (2011) Target-specificity of feral pig baits under different conditions in a tropical rainforest. Wildl Res 38: 370-379

Chapin FS, Zavaleta ES, Eviner VT, Naylor RL, Vitousek PM, Reynolds HL, Hooper DU, Lavorel S, Sala OE, Hobbie SE, Mack MC, Diaz S (2000) Consequences of changing biodiversity. Nature 405: 234-242

Choquenot D, Ruscoe W (1999) Assessing the effect of poisoning programs on the density of non-target fauna: design and interpretation. N Z J Ecol 23: 139-147 
Christian KA, Gavin BS, Shannahan ST (1996) Solar absorbance of some Australian lizards and its relationship to temperature. A J Zool 44: 59-67

Courchamp F, Chapuis JL, Pascal M (2003) Mammal invaders on islands: impact, control and control impact. Biol Rev 78: 347-383

Croll DA, Maron JL, Estes JA, Danner EM., Byrd GV (2005) Introduced predators transform subarctic islands from grassland to tundra. Science 307: 1959-1961

de Tores P J, Sutherland DR, Clarke J R, Hill R F, Garretson S W, Bloomfield L, Strümpher L, Glen AS, Cruz J (2011) Assessment of risks to non-target species from an encapsulated toxin in a bait proposed for control of feral cats. Wildl Res38: 39-50

DEWHA 2008. Background document for the Threat Abatement Plan for predation by feral cats. Department of Environment, Water, Heritage and the Arts (DEWHA), Canberra.

Davidson RS, Armstrong DP (2002) Estimating impacts of poison operations on nontarget species using mark-recapture analysis and simulation modelling: an example with saddlebacks. Biol Cons 105: 375-381

Dickman CR (1996) Overview of the Impacts of Feral Cats on Australian Native Fauna. Australian Nature Conservation Agency: Canberra. 
Forster G (2009) Non-target species uptake of feral cat baits containing Rhodamine B.

BSc (Hons) thesis. Department of Agricultural Sciences, Latrobe University,

Bundoora.

Glen AS, Gentle MN, DickmanCR (2007) Non-target impacts of poison baiting for predator control in Australia. Mam Rev 37: 191-205

Hadfield J (2010) MCMC methods for Multiresponse Generalised Linear Mixed Models: The MCMCglmm R Package." J Stat Software 33: 1-22

Hetherington CA, Algar D, Mills H, Bencini R (2007) Increasing the target-specificity of ERADICAT ${ }^{\circledR}$ for feral cat (Felis catus) control by encapsulating a toxicant. Wildlife Research 34: 467-471

Huey RB (1982) Temperature, physiology, and the ecology of reptiles, pp. 25-9 1. In C. Gans and F. H. Pough (eds.), Biology of the Reptilia, Vol. 12. Academic Press, N.Y.

Jessop TS, Lockwood T, Urlus J, Gillespie G (2010) Preying possum: assessing the diet of $V$. varius from forest of South Eastern Australia. Biawak 4: 59-66

Jessop TS, Smissen P, Scheelings F, Dempster T (2012) Demographic and Phenotypic Effects of Human Mediated Trophic Subsidy on a Large Australian Lizard (Varanus varius): Meal Ticket or Last Supper? PLoSONE 7(4): e34069. Doi :10.1371/journal.pone.0034069. 
Johnston M, Algar D, Hamilton N, Lindeman M (2010) A bait efficacy trial for the management of feral cats on Christmas Island. Arthur Rylah Institute for Environmental Research Technical Report Series No. 200. Department of Sustainability and Environment, Heidelberg, Victoria.

Johnston M, Algar D, O’Donoghue M, Morris J (2011) Field efficacy of the Curiosity feral cat bait on three Australian islands. In: Veitch, C. R.; Clout, M. N. and Towns, D. R. (eds.). 2011. Island invasives: eradication and management, pp. 182-187. IUCN, Gland, Switzerland.

Johnston MJ (2012) Field assessment of the Curiosity ${ }^{\circledR}$ bait for management of feral cats after fire at Wilsons Promontory National Park: Black Saturday Victoria 2009Natural values fire recovery program. Department of Sustainability and Environment, Heidelberg, Victoria. Pp. 39.

Kearney M, Porter WP (2004) Mapping the fundamental niche: Physiology, climate, and the distribution of a nocturnal lizard. Ecology 85: 3119-3131

Kearney M, Porter WP (2009) Mechanistic niche modelling: combining physiological and spatial data to predict species' ranges. Ecol Let 12: 334-350.

Kearney M, Shine R, Porter WP (2009) The potential for behavioral thermoregulation to buffer "cold-blooded" animals against climate warming. Proc Nat Acad Sci USA 106: $3835-3840$ 
Kearney M, Phillips BL, Tracy CR, Christian KA., Betts G, Porter WP, (2008)

Modelling species distributions without using species distributions: the cane toad in Australia under current and future climates. Ecography 31: 423-34

Kinnear JE, Sumner NR, Onus ML (2002) The red fox in Australia - an exotic predator turned biocontrol agent. Biol Cons 108, 335-359

Kinnear JE, Krebs CJ, Pentland C, Orell P, Holme C, Karvinen R, (2010) Predatorbaiting experiments for the conservation of rock-wallabies in Western Australia: a 25year review with recent advances. Wildl Res 37: 57-67

Lunn D J, Thomas A, Best N, Spiegelhalter D (2000). WinBUGS - a Bayesian modelling framework: concepts, structure, and extensibility. StatComp 10: 325-337

MacKenzie D I, Nichols JD, Royle JA, Pollock KH, Bailey LL, Hines JE (2006) Occupancy estimation and modeling. Academic Press, Burlington MA.

Marks CA, Johnston MJ, Fisher PM, Pontin K, Shaw MJ (2006) Differential particle size: promoting target-specific baiting of feral cats. J Wildl Man 70: 1119-1124

McCarthy MA (2007) Bayesian methods for ecology. Cambridge University Press. Cambridge. 
McIlroy J, King DR, Oliver AJ (1985) The sensitivity of Australian animals to 1080 poison VIII. Amphibians and reptiles. A Wildl Res 12: 113118

Moseby KE, Stott J, Crisp H(2009) Improving the effectiveness of poison baiting for the feral cat and European fox in northern South Australia: the influence of movement, habitat use and activity. Wildl Res 36: 1-14

Moseby KE, Hill BM (2011) The use of poison baits to control feral cats and red foxes in arid South Australia I. Aerial baiting trials. Wildl Res 38: 338-349

Moseby KE, Read JL, Munro N, Galbraith B, Newport J, Hill

BM (2011) The use of poison baits to control feral cats and red foxes in arid South Australia II. Bait type, placement, lures and non-target uptake. Wildl Res 38: 350-358

Murphy EC, Shapiro L, Hix S, MacMorran D, Eason CT (2011) Control and eradication of feral cats: field trials of a new toxin. In: Veitch CR, Clout MN and Towns DR (eds.). Island invasives: eradication and management, pp. 213-216. IUCN, Gland, Switzerland

Owens IPF, Bennett PM (2000) Ecological basis of extinction risk in birds: Habitat loss versus human persecution and introduced predators. Proc Nat Acad Sci USA 97: $12144-12148$ 
Porter WP, Mitchell JW (2006) http://www.patentstorm.us/patents/7155377-fulltext. html, ed. U.P. Office (Wisconsin Alumni Research Foundation).

Porter WP (1989) New animal models and experiments for calculating growth potential at different elevations. Physiol Zool 62: 286-313

PorterWP, Mitchell JW, Beckman WA, DeWitt CB (1973) Behavioral implications of mechanistic ecology-thermal and behavioral modeling of desert ectotherms and their microenvironment. Oecologia 13:1-54

R Development Core Team (2007) R: A language and environment for statistical computing. R Foundation for Statistical Computing, Vienna, Austria. ISBN 3900051-07-0, URL http://www.R-project.org.

Reddiex B, Forsyth DM, McDonald-Madden E, Einoder LD, Griffioen PA, Chick RR, Robley AJ, (2006) Control of pest mammals for biodiversity protection in Australia. I. Patterns of control and monitoring. Wildl Res 33: 691-70

Risbey DA, Calver MC, Short J, Bradley JS, Wright IW (2000) The impact of cats and foxes on the small vertebrate fauna of Heirisson Prong, Western Australia. II. A field experiment. Wildl Res 27: 223-235

Ritchie EG, Johnson CN (2009) Predator interactions, mesopredator release and biodiversity conservation. Ecol Lett 12: 982- 998 
Saunders GR, Gentle MN, Dickman CR (2010) The impacts and management of foxes Vulpes vulpes in Australia. Mam Rev 40: 181-211

Short J, Calver MC, Risbey DA (1997a) Control of feral cats for nature conservaton I. Field tests of four baiting methods. Wildl Res 24: 319-326.

Short J, Turner B, Risbey DA, Carnamah R (1997) Control of feral cats for nature conservation. II. Population reduction by poisoning. Wildl Res 24: 703-714.

Spiegelhalter DJ, Best NG, Carlin BP, van der Linde A (2002) Bayesian Measures of Model Complexity and Fit. J Roy Stat Soc B 64: 583-639

Sturtz S, Ligges U, Gelman A (2005) R2WinBUGS: A Package for Running WinBUGS from R. J Stat Soft 12: 1-16

Sutherland DR, Glen AS, de Tores PJ (2011) Could managing mammalian carnivores lead to mesopredator release of carnivorous reptiles? Proc Roy Soc B 278: 641-648

Veltman CJ, Westbrooke IM (2011) Forest bird mortality and baiting practices in New Zealand aerial 1080 operations from 1986 to 2009. N Z J Ecology 35: 21-30 
Table 1. Effects of environmental parameters on total daily cat bait removal by $V$. varius across 60 bait stations in East Gippsland. Table describes number of parameters (K), Deviance Information Criterion (DIC), change in DIC ( $\triangle \mathrm{DIC})$ relative to the most parsimonious model and model weight $(\boldsymbol{\omega})$.

\begin{tabular}{lllll}
\hline Model & K & DIC & $\Delta$ DIC & $\boldsymbol{\omega}$ \\
\hline dsr*dmt & 4 & 755.59 & 0.00 & 0.93 \\
dsr+dmt & 3 & 760.68 & 5.09 & 0.07 \\
daily maximum temperature(dmt) & 2 & 775.06 & 19.47 & 0.00 \\
daily solar radiation(dsr) & 2 & 779.19 & 23.60 & 0.00 \\
daily rain fall & 2 & 803.07 & 47.48 & 0.00 \\
null & 1 & 803.31 & 47.72 & 0.00 \\
\hline
\end{tabular}


Table 2. Ranking for linear and non-linear regression models relative to the null model examining the relationship between predicted annual daily activity duration and annual daily temperature for $V$. varius in East Gippsland. Table describes estimated number of parameters $\left(\mathrm{P}_{\mathrm{D}}\right)$, Deviance Information Criterion (DIC), change in DIC $(\triangle \mathrm{DIC})$ relative to the most parsimonious model and model weight $(\boldsymbol{\omega})$.

\begin{tabular}{lcccc}
\hline Model & $\mathbf{P}_{\mathbf{D}}$ & DIC & $\Delta$ DIC & $\boldsymbol{\omega}$ \\
\hline logistic & 2.40 & 1540.61 & 0 & 1.00 \\
power & 3.00 & 1597.61 & 56.99 & 0.00 \\
null & 2.00 & 1733.02 & 192.41 & 0.00 \\
linear & 3.10 & 3862.30 & 2321.69 & 0.00 \\
\hline
\end{tabular}


Table 3. Ranking for linear and non-linear regression models relative to the null model examining the relationship between predicted daily activity duration and daily bait take by $V$. varius in East Gippsland. Table describes estimated number of parameters $\left(\mathrm{P}_{\mathrm{D}}\right)$, Deviance Information Criterion (DIC), change in DIC $(\Delta \mathrm{DIC})$ relative to the most parsimonious model and model weight $(\boldsymbol{\omega})$.

\begin{tabular}{llrcc}
\hline Model & $\mathbf{P}_{\mathbf{D}}$ & \multicolumn{1}{l}{ DIC } & $\Delta \mathrm{DIC}$ & $\boldsymbol{\omega}$ \\
\hline linear & 3.10 & -87.90 & 0.00 & 0.43 \\
power & 3.00 & -88.70 & 0.80 & 0.29 \\
logistic & 4.00 & -88.90 & 1.00 & 0.26 \\
null & 2.00 & -80.50 & 7.40 & 0.01 \\
\hline
\end{tabular}




\section{Figure Captions}

Fig. 1 The effects of daily maximum temperature (A) and solar radiation (B) were the two most influential parameters for explaining percentage total daily cat bait removal by $V$. varius across 60 bait stations in Far East Gippsland. The data is fitted with the predicted logistic functions (solid line) and associated standard errors (dashed lines).

Fig. 2 Niche Mapper estimates of predicted daily and annual activity patterns for $V$. varius inhabiting coastal forest in East Victoria. These two figures indicate the influence of daily maximum temperatures on predicted daily duration of $V$. varius activity. Figure (A) depicts a logistic curve (solid line) with associated standard error (dashed lines) to depict the non-linear relationship between daily activity duration and daily maximum temperature. Figure (B) depicts the annual pattern of predicted seasonal activity levels across Eastern Victoria under normal cloud cover and indicates clear seasonal variation in the predicted activity of $V$. varius.

Fig. 3 The relationship between predicted daily activity and percentage total bait take for V. varius in East Gippsland Victoria. A power function (solid line) and associated standard error (dashed lines) is fitted to the data to best demonstrate the pattern of this relationship. 

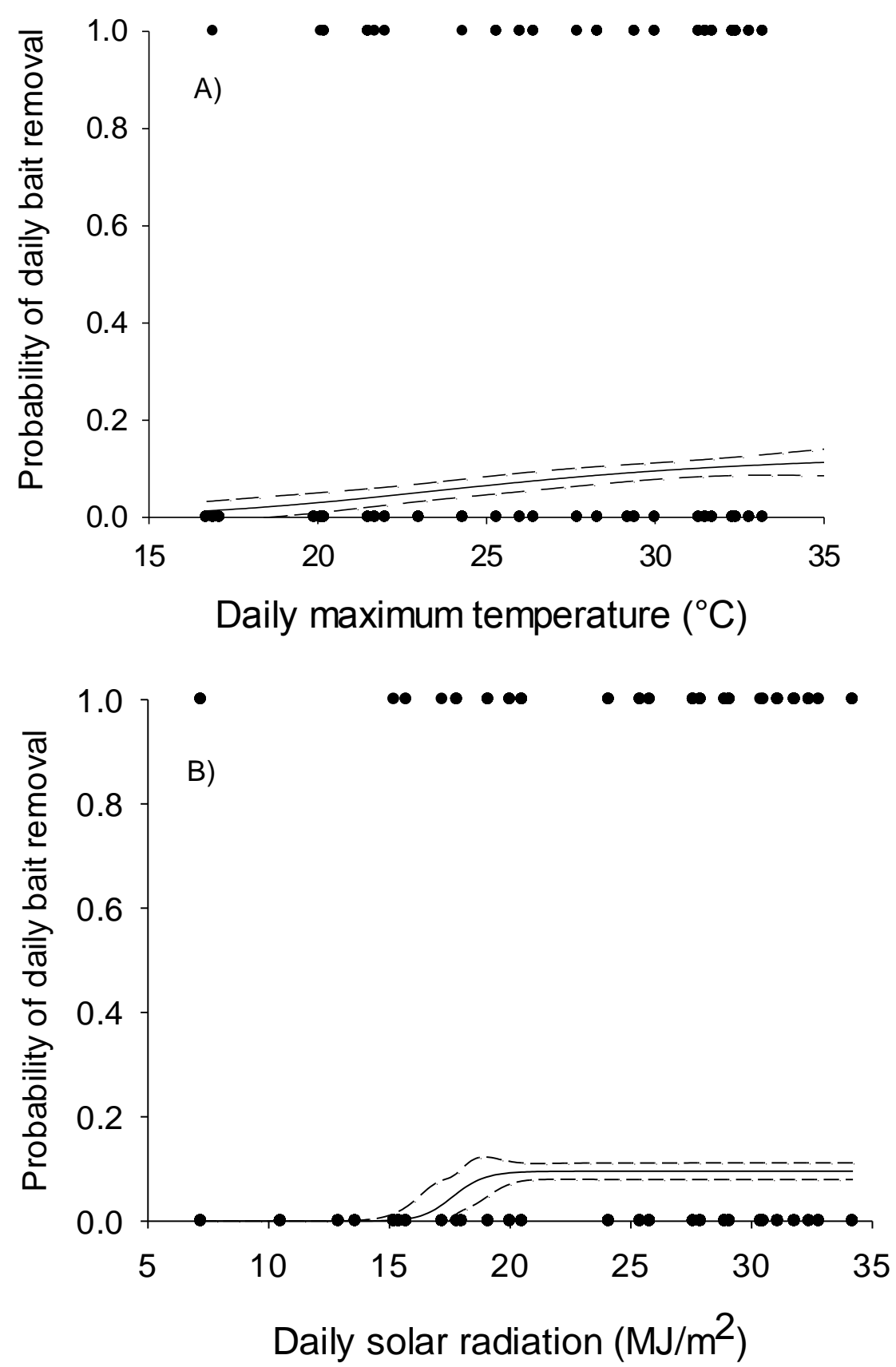

Figure 1. 

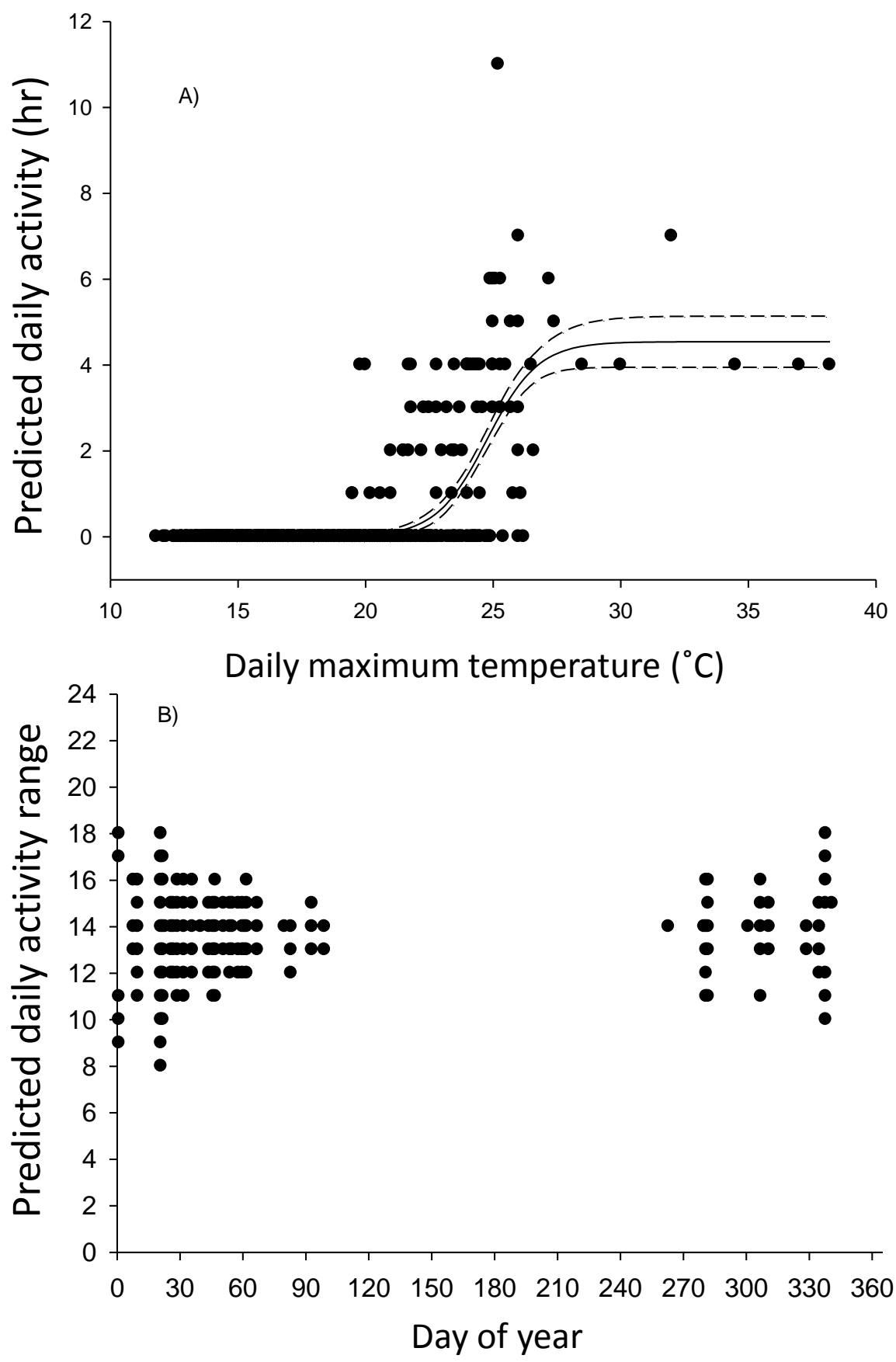

Figure 2. 


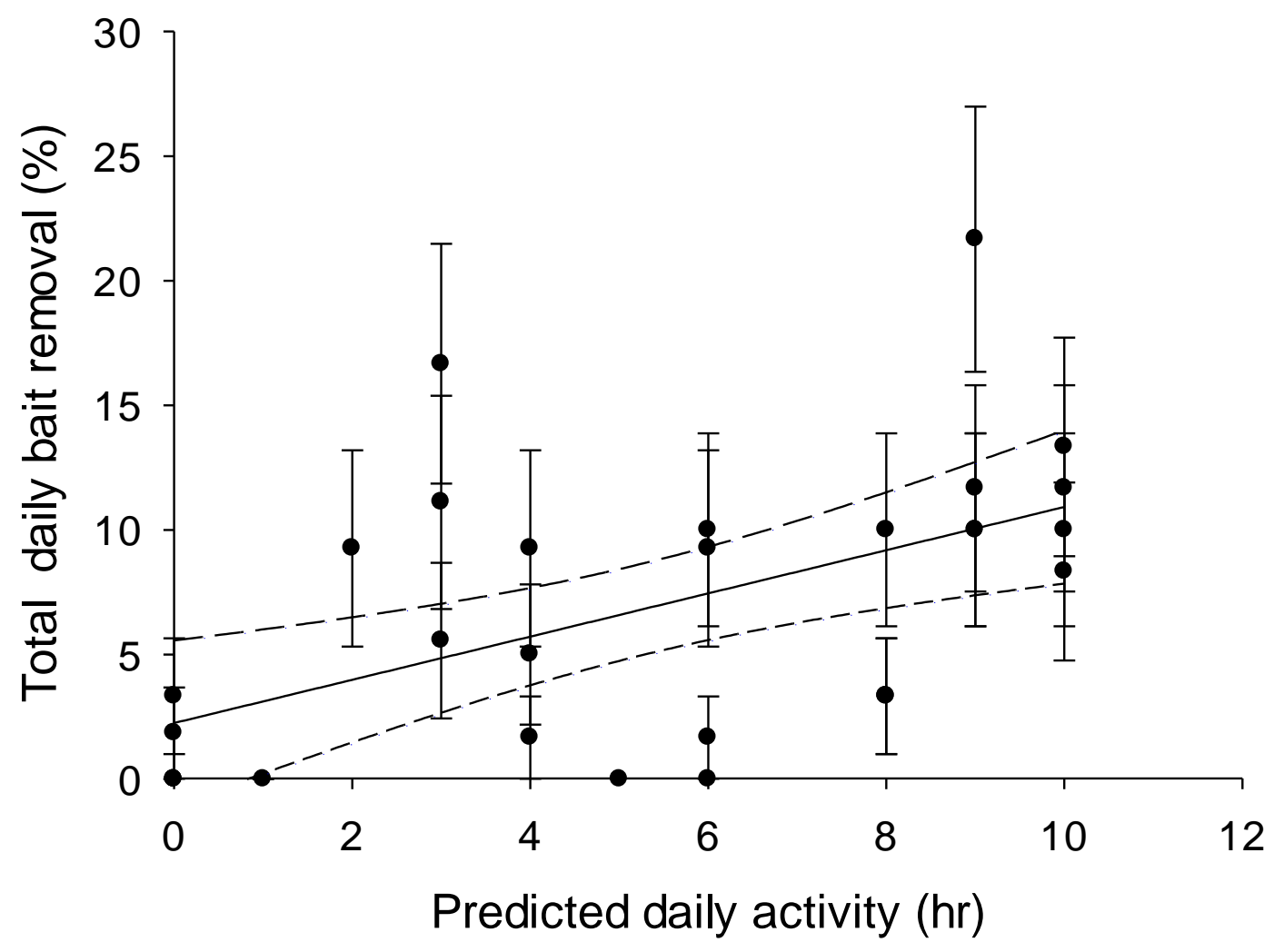

Figure 3. 


\section{University Library}

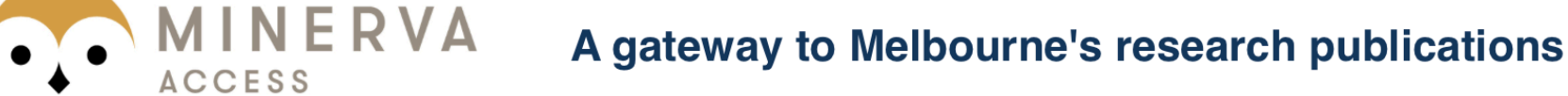

Minerva Access is the Institutional Repository of The University of Melbourne

\section{Author/s:}

Jessop, TS;Kearney, MR;Moore, JL;Lockwood, T;Johnston, M

Title:

Evaluating and predicting risk to a large reptile (Varanus varius) from feral cat baiting protocols

\section{Date:}

2013-08-01

\section{Citation:}

Jessop, T. S., Kearney, M. R., Moore, J. L., Lockwood, T. \& Johnston, M. (2013).

Evaluating and predicting risk to a large reptile (Varanus varius) from feral cat baiting protocols. BIOLOGICAL INVASIONS, 15 (8), pp.1653-1663. https://doi.org/10.1007/ s10530-012-0398-3.

Persistent Link:

http://hdl.handle.net/11343/283074 